\title{
Diseño Industrial en el Ecuador: Importancia, Historia y Oportunidades
}

Industrial Design in Ecuador: Importance, History and Opportunities

\begin{tabular}{c} 
Guanoluisa R. ${ }^{1} ;$ Bravo. D. ${ }^{2}$ \\
1 Universidad Central del Ecuador, Facultad de Ingeniería Ciencias Físicas y Matemática. Quito, Ecuador \\
e-mail: rjguanoluisa @uce.edu.ec \\
${ }^{2}$ Universidad Politécnica de Valencia, Escuela Técnica Superior de Ingeniería del Diseño. \\
Camí de Vera. Valencia, España. \\
e-mail: delydis@ gmail.com \\
\hline Información del artículo \\
Recibido: febrero 2020 \\
Aceptado: marzo 2020 \\
\hline
\end{tabular}

\section{RESUMEN}

El presente artículo reseña y estructura el inicio del Diseño Industrial en el Ecuador, presentando una evolución del mismo dentro de los ejes académicos, industriales y económicos. Exhortando a los distintos agentes del Diseño Industrial para la generación de delimitantes históricas y objetivas. En el desarrollo de este artículo, se denotará la importancia de la incorporación de las competencias del Diseño Industrial dentro de los factores productivos, de desarrollo de innovación y valor agregado dentro del mercado ecuatoriano.

Palabras clave: Diseño Industrial, Historia, Factores Productivos, Competencias.

\begin{abstract}
The present paper reviews and structure the beginning of Industrial Design in Ecuador, presenting its evolution involving academic, industrial and economic axes. Exhorting to the different agents of Industrial Design to generate a historic and objective delimitation. In the development of this paper, the denotation of the importance of the incorporation of the competences of Industrial Design within the productive factors, the development of the innovation, and the added value in the Ecuador market are been pointed out.
\end{abstract}

Keywords: Industrial Design, History, Productive Factors, Competencies. 


\section{Introducción}

La concepción y creación de objetos se remonta a la aparición del ser humano, como método para la supervivencia, según el contexto específico en el que se ha desarrollado. El ser humano ha sido capaz de crear herramientas e utilitarios adecuadas que faciliten su adaptación al medio. Esta concepción bajo necesidades y contexto específicos representan la actividad de diseño.

"El origen del concepto de Diseño Industrial, viene con la Revolución Industrial que tuvo lugar en Inglaterra a mediados del S.XVIII" [1]. La revolución industrial permitió la incorporación de maquinaria en el proceso de manufactura de productos. "Previamente a esta revolución, el diseño y la producción estaban centrados en el artesano, quien creaba desde el principio hasta el fin el producto" [2]. Aunque la conceptualización del termino diseño industrial es presentado tras la revolución industrial. "La disciplina como tal nace a finales del S.XIX con el movimiento británico Arts and Crafts que en realidad cuestionaba y criticaba la fabricación industrializada y la pobreza de la producción de esos objetos cotidianos de la sociedad" [1]. A los esfuerzos del movimiento Arts and Crafts se suman la conceptualización de la disciplina mediante la escuela de arquitectura y diseño alemana Bauhaus a la que se le otorgan objetivos de "suprimir las barreras entre el arte, la artesanía y la industria y poner en común estas actividades al servicio de la construcción del futuro; educar por el arte, la acción y el trabajo; hacer del trabajo una herramienta para adquirir y cultivar conocimientos tanto intelectuales como emocionales [3]".

En Latinoamérica, "es posible percatarse de que ha sido una disciplina importada, ya que los primeros profesionales vinieron de Europa. Estas personas trajeron un quehacer fuertemente influenciado por la experiencia Bauhaus, la cual intentaron aplicar a nuestro proceso de industrialización tan peculiar. [4]"

Pero tanto la historia del diseño como específicamente el diseño industrial en Latinoamérica presentan carencias de una estructuración especifica e objetiva. "Se han comenzado a publicar historias locales con sólida y abundante documentación primaria (principalmente en Brasil, Chile y México)" [5].
Dentro del desarrollo ecuatoriano de esta actividad, la falta de delimitación y acciones específicas dentro de la disciplina generan una interacción errónea dentro del entendimiento de las actividades del diseño industrial en sus campos de acción.

La generación errónea del entendimiento y reconocimiento del diseño industrial frena el desarrollo del mismo. A el diseño industrial se le atribuye el embellecimiento de objetos. Es decir, la pre-concepción del diseñador industrial es la de mejorar las atribuciones superficiales de los objetos sin considerar su desarrollo proyectual. Lo que difiere de la concepción de la disciplina "Esta nueva actividad profesional el Diseño Industrial, si bien está enmarcada por la estética, no pertenece al campo del arte, sino de la tecnología, su actividad no consiste (como sucedía antes) en embellecer los productos agregándoles ornamentos que nada tienen que ver con su funcionalidad [3]".

Por lo cual, la presente investigación busca mitigar el desconocimiento abordando estos nexos bajo tres ámbitos específicos.

Investigar y establecer conceptos claros del Diseño Industrial y sus campos de acción en el ejercicio profesional.

La historia del diseño industrial ecuatoriano desde la perspectiva académica, política e industria; así, como sus mayores exponentes dentro de las empresas público/privadas.

Análisis del posible impacto económico del nexo entre Diseño Industrial y el desarrollo productivo ecuatoriano.

Estos ejes investigativos tienen la intención de dilucidar en los profesionales del Diseño Industrial tanto como en las empresas su posición frente a los retos de ideación, innovación y producción.

\section{Metodología}

Basados en el propósito central de la investigación de proporcionar un levantamiento histórico del Diseño Industrial en el Ecuador. El desarrollo de la presente investigación es de carácter cualitativa debido a su proceso inductivo, interpretativo e iterativo y recurrente persiguiendo los objetivos de presentar una visión detallada de la historia del D.I. en el Ecuador ayudando a comprender las cir- 
cunstancias específicas de la disciplina en relación a su entorno [6].

Para el inicio de la investigación se realizó una revisión literaria de fuentes primarias y secundarias, para determinar el hilo cronológico a seguir.

Sujetos: Dentro de la investigación los sujetos son los agentes participes de los ejes principales de la investigación dentro de la academia se determinó Universidades e Institutos de formación profesional que han determinado la formalización del diseño industrial en orden cronológico y la influencias por las cuales fueron creadas, Industrias que involucraron o involucran planes de diseño industrial dentro del desarrollo productivo de sí mismas y Principales exponentes del diseño industrial que han fomentado la creación de nuevos productos dentro de las fibras nacionales e internacionales de diseño.

Técnicas e Instrumento: El desarrollo de la investigación es una recolección y levantamiento de información mediante técnicas de observación, entrevistas, inmersión en el ambiente y análisis de datos.

Es así, que la investigación establecerá un primer acercamiento de los hechos que han permitido un crecimiento del diseño industrial tanto como los eventos que presentaron un retraso del crecimiento de la disciplina dentro del contexto territorial ecuatoriano.

\subsection{Definición de Diseño Industrial}

El diseño Industrial de acuerdo a la definición de la Organización Mundial del diseño (WDO, por sus siglas en inglés):

“Un proceso estratégico de resolución de problemas que impulsa la innovación, desarrolla el éxito comercial y conduce a una mejor calidad de vida a través de productos, sistemas, servicios y experiencias innovadoras." [7].

Este concepto reúne de manera acertada la manera de actuar del diseño industrial delimitando su amplio campo de acción.
Tomás Maldonado (1977) señalaba que “el diseño industrial es una actividad proyectual que consiste en determinar las prioridades formales de los objetos producidos industrialmente" [8].

Este concepto establecido por Tomas Maldonado discierne las conjeturas del diseño y su aplicación como uso ornamental y sin valor, evidenciando la amplitud del diseño industrial en un contexto de creación proyectual y adaptación a la Industria.

Insertando las definiciones del diseño industrial se debe desarrollar una profundización de las actividades que se le atribuyen al diseñadorindustrial.

"El Diseñador Industrial, al realizar el diseño, parte del análisis:

- De los requerimientos y las exigencias sociales y económicas;

- De la función y de lo que debe expresar la forma del producto;

- Del hombre como usuario;

- De los materiales más idóneos;

- De las técnicas constructivas más razonables; etc." [3].

\subsection{Campos de acción del Diseño Industrial}

De acuerdo a la definición y a la naturaleza del diseño industrial sus posibilidades son amplias debido a la interdisciplinaridad. Para ejemplificar la amplitud de los campos de acción se toma como referencia el de Diseño Industrial de Rodríguez (2000), alineados en la Tabla 1 Campos de acción que abarca la profesión de Diseño Industrial donde se evidencian algunos de los campos donde se desenvuelve el diseñador industrial. 
Tabla 1. Campos de acción que abarca la profesión de Diseño Industrial [9].

\section{Campos de acción que abarca la profesión de Diseño Industrial.}

Vivienda, participando en el diseño de:

- Elementos prefabricados para la construcción.

- Mobiliario en general

- Línea blanca

- Aparatos electrodomésticos

- Sistemas de alumbrado, calefacción, refrigeración, cocción y Sanitarios

- Elementos para la recreación(juguetes).

Servicios públicos participando en el diseño de :
- Mobiliario urbano

- Equipos de limpieza Dispositivos para el mejoramiento ambiental.

- Elementos para la recreación y esparcimiento Sistemas de rescate y auxilio.

- Medios de transporte Sistemas masivos de comunicación Sistemas de inhumaciones.
Educación participando en el diseño de:

\begin{tabular}{l} 
Energía, participando en el diseño de: \\
\hline $\begin{array}{l}\text { Salud, participando en el diseño de: Ins- } \\
\text { trumental médico, Equipo médico. }\end{array}$
\end{tabular}

- Material didáctico

- Mobiliario

- Instrumental para laboratorios y talleres.

- Elementos prefabricados para la construcciónde instituciones para la enseñanza.

- Dispositivos de captación. (solares,eólicos).

- Dispositivos de extracción (petróleo).

- Dispositivos de transformación Instalaciones en general.

- Instrumental médico.

- Equipo médico.

- Mobiliario médico, Medios de transporte, Envase empaque y almacenamiento

- Aparatos de rehabilitación. 


\section{Campos de acción que abarca la profesión de Diseño Industrial.}

Alimentación (agricultura, ganadería. pesca') participando en el diseño de:

- Utensilios, herramientas y máquinas para las distintas faenas laborales.

- Sistemas de almacenamiento y conservación (Envase. empaque y embalaje).

- Medios de transportación.

- Sistemas de riego.

Industrias (de procesamiento de alimentos y elaboración de Bebidas; tabacaleras; textiles, del vestido y del cuero; de la madera y sus Productos; del Papel y sus productos; impresoras y editoriales; químicas, petroquímicas y carboneras; metalúrgicas básicas y sus productos, de maquinaria y equipo), participando en el diseño de:
- Sistemas de protección

- Utensilios, herramientas, máquinas y autómatas

- Envase, empaque, embalaje

- Medios de transportación

- Sistemas de almacenamiento y conservación
Industria automotriz, participando en el diseño de:
- Vestiduras e interiores Carrocerías

- Utensilios, herramientas y máquinas.

- Sistemas de transformación o maquinado

- Medios de transportación.

\subsection{Primeras huellas del Diseño Industrial en el Ecuador}

En Ecuador, el inicio del diseño industrial es difuso y poco delimitado, las aproximaciones que se han generado sobre su historia involucran a las distintas aristas del diseño, las artes y oficios. Por lo cual, la primera aproximación surge con el Panama Hat, un sombrero a base de paja toquilla planta endémica ecuatoriana con nombre científico "carludovica palmata", el producto toma su nombre debido a que:

"Desde Panamá el sombrero se internacionalizó y la gente empezó a denominarlo 'Panama Hat', sin saber que el sombrero era realmente ecuatoriano" [10]
Kleyder Pachay, presidente de la Unión de Tejedores de Sombrero de Paja Toquilla de Montecristi, quien sostiene que se remonta a la visita del entonces presidente de EE.UU. Theodore Roosevelt a Panamá, cuando fue a supervisar la obra del canal, en 1906 "Las autoridades optaron por regalar un sombrero a todos los invitados de este magno evento" [11]

De acuerdo a el Ministerio del Turismo Ecuatoriano el origen data de 1630 entre la combinación de esta materia prima y basado en los modelos de sombrero español. Tomando una fuerza productiva en 1854 donde la exportación de sombreros de paja toquilla superó al cacao; hacia 1863 se exportó desde el Puerto de Guayaquil 500.000 sombreros [12]. Aunque la producción de este sombrero es manual, su diseño y producción es considerada como el inicio de diseño de productos en el Ecuador. 


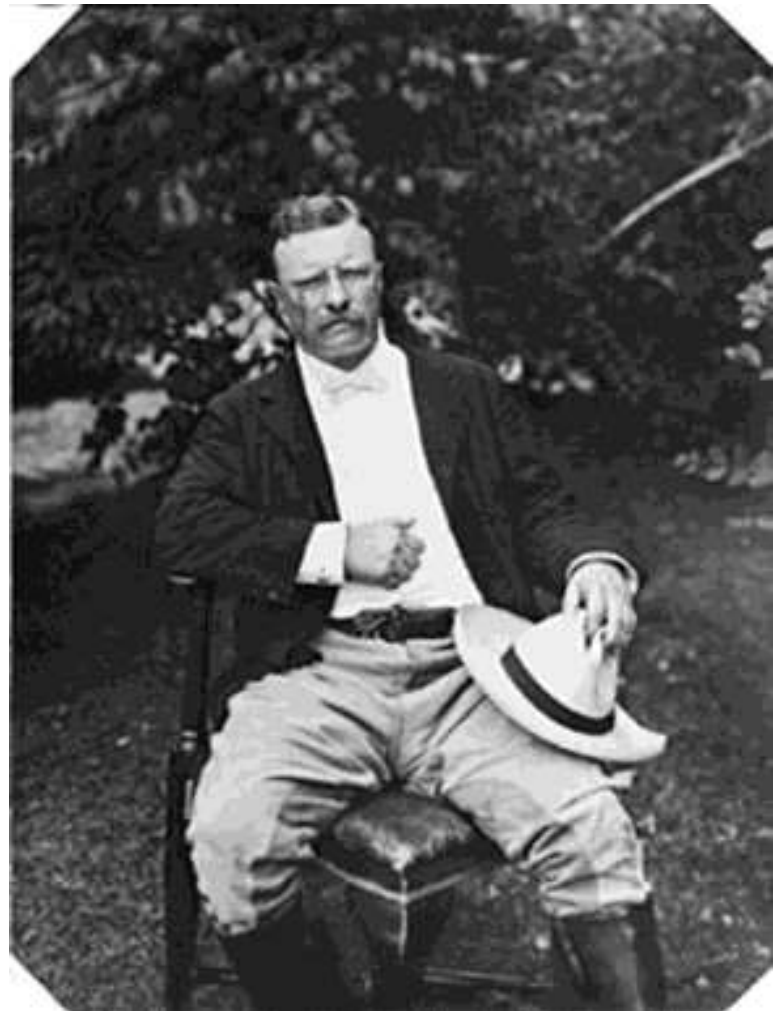

Figura 1. Retrato de Roosevelt de 1903, tres años antes de su viaje a Panamá[13].

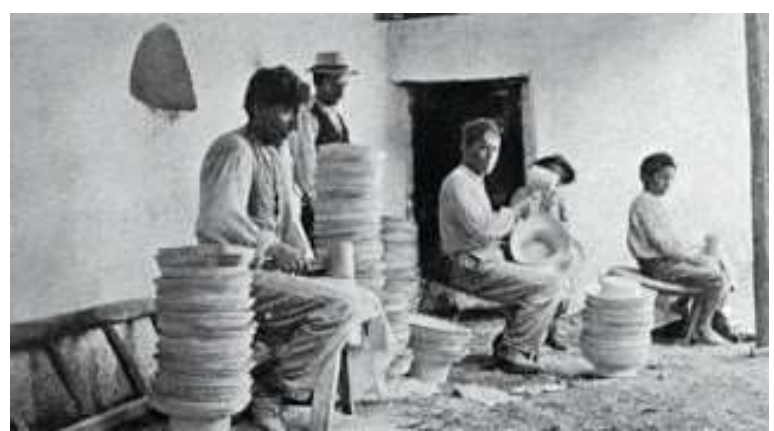

Figura 2. Artesanos tejiendo sombreros de paja toquilla [14].

Se considera como una antesala hacia el desarrollo del diseño industrial, debido a sus características de producción en masa, proceso específico y controlado y al desarrollo de modelos y de patrones.

Un gran referente del diseño de mobiliario dentro del territorio ecuatoriano es la empresa Artículos de Acero, S.A. (ATU). "Fundada en 1940 por Hans Rothschild como, The Rothschild Metal Works con la fabricación de recipientes de acero para lácteos, en 1944, ATU se especializa en muebles de oficina a nivel nacional y comienza a exportar en el año de 1992" [15]. El contexto histórico en el que se desarrolla ATU es bajo un auge de explotación de campos petroleros. Para resolver la gran demanda de equipamiento de oficinas debido a la migración de la población de pueblos a las ciudades luego de la bonanza económica que las explotaciones petroleras proporcionaron. [5].

"ATU es una empresa emblemática ecuatoriana que, desde su fundación, se convierte en líder en el segmento de mobiliario de oficina y modulares por su diseño y calidad reconocida en el mercado nacional e internacional. Su capacidad instalada de fábrica en el Ecuador, le permite una producción flexible, eficiente y de gran volumen, otorgando una garantía inigualable en elmercado" [15].

Los Hitos de la empresa recopilados por el Grupo Ekos se presentan en las siguientes imágenes:
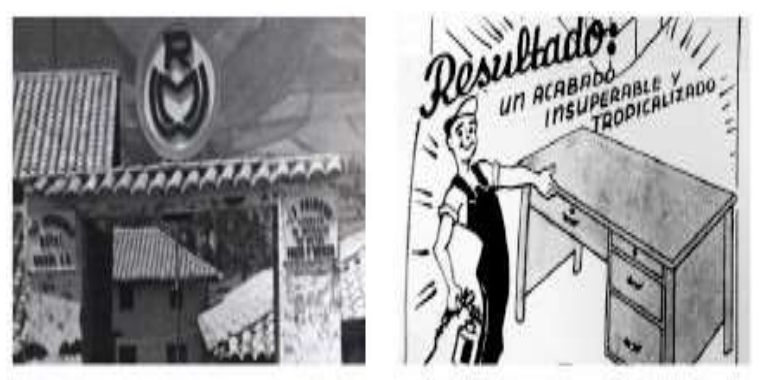

1940

1944

Se funda The Rothschild Metal Works ATU se especializa en la fabricación por Hans Rothschild, con la fabricación de muebles de oficina a nivel nacional, de recipientes de acero para lácteos.

siendo los primeros en el Ecuador.
Figura 3 Hitos de la marca ATU [15].

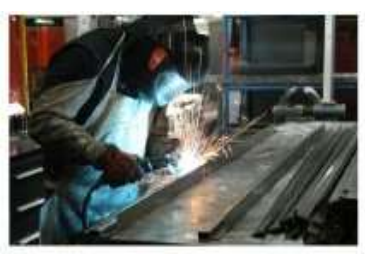

1992

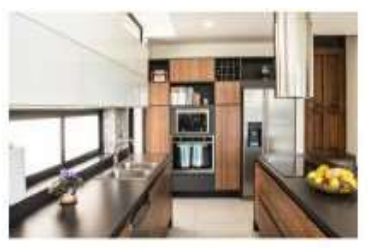

2017

Se inician las operaciones de exportación, llegando a Estados Unidos., Colombia, Bolvia, Costa Rica, Panamá, Perú, Venezuelay Chile.

as marcas ATU y Hogar 2000 se fusionan con la adquisición de las empresas Muepramodul y Hogar 2000 por parte de ATU.

Figura 4. Hitos de la empresa ATU (2) [15]. 
Aunque ATU poseía una gran parte del mercado de mobiliario de oficinas y era considerada como una de las empresas más estables en términos económicos. El 26 de enero de 2018 mediante un cartel en su puerta de ingreso anunciaba su quiebra [12]. Posteriormente, el 14 de marzo de 2019, ATU fue declarada en disolución por la Superintendencia de Compañías [13]. Después del cierre definitivo de ATU su presencia dentro de la web y archivos son de difícil acceso por lo cual este articulo presenta solo algunas de las obras de ATU recopilados de catálogos y entrevistas. A pesar, de su gran importancia y transcendencia dentro del diseño industrial ecuatoriano.

\section{Escritorios Ejecutivos Chieti}

La concepción Chieti combina diferentes materiales en su estructura y tableros de madera en contrastes sobrios y sutiles. Chieti es un elemento decorativo que llega a ser una atractiva tipología mobiliaria, sencilla y elegante [18].

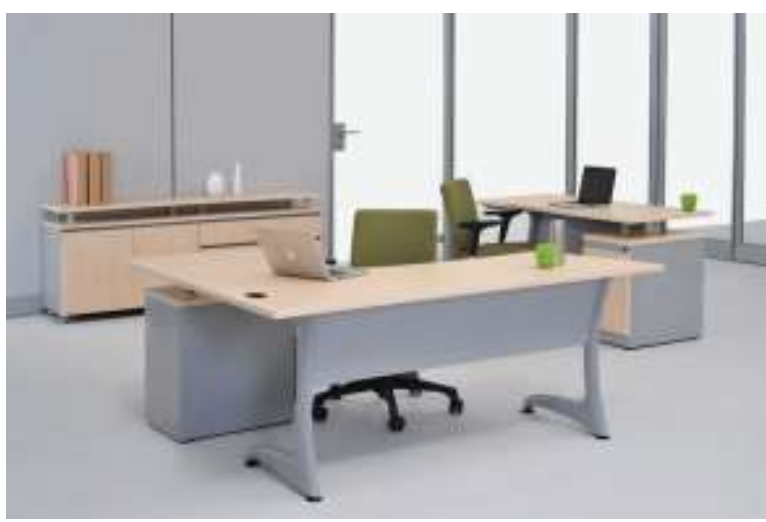

Figura 5. Escritorios Ejecutivos Chieti [18].

\section{Salas de Espera y Lounges Tandem}

Una gran apuesta en el equipamiento de espacios en áreas de espera, inspiradas en formas curvas y estudios de diseño ergonómico para mejorar el confort de los usuarios [18]

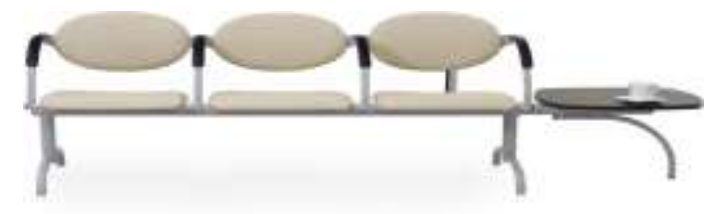

Figura 6. Salas de Espera y lounges Tandem [19].

\section{Archivación Cabinet}

Elementos de archivo - almacenaje que se adaptan a cualquier configuración del espacio, ofreciendo sistemas para diferentes formas de archivar y guardar.

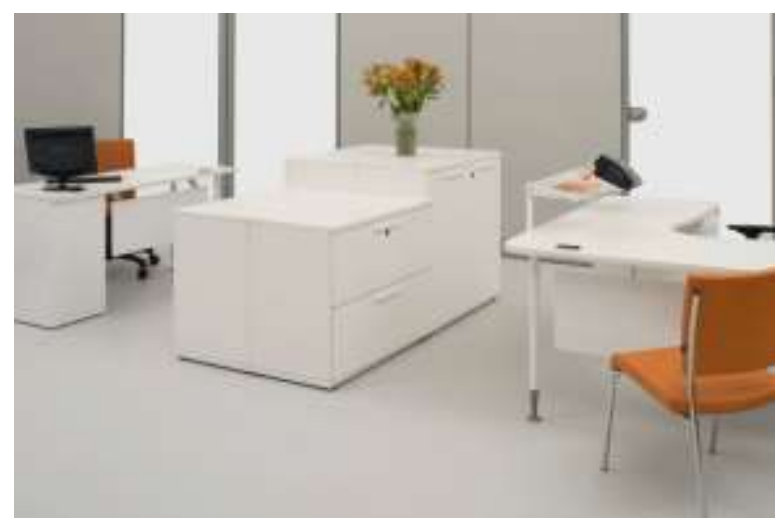

Figura 7. Archivación Cabinet [20].

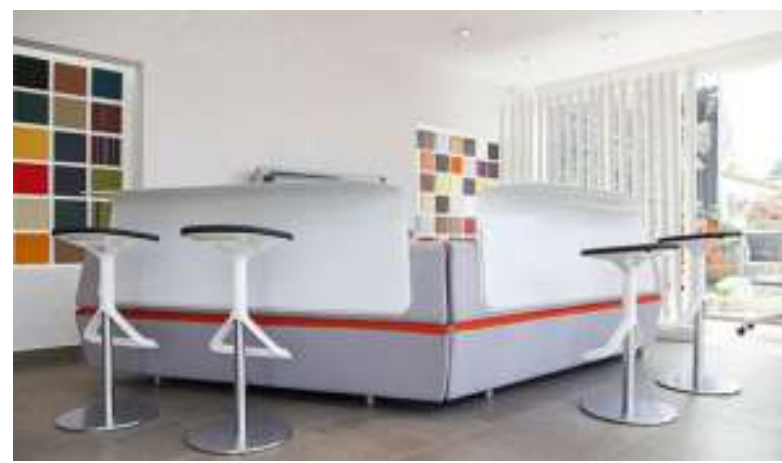

Figura 8. Counter de Showroom ATU [21].

El desarrollo de productos industriales continúa en el Ecuador con Pica Plásticos Industriales C.A quienes inicia sus actividades el 1 de septiembre de 1961, en la ciudad de Guayaquil. Dos máquinas inyectoras y seis obreros, elaboraron el primer producto una "Cubeta de Hielo". En 1965 Se produce el crecimiento más agresivo de la compañía, PICA consolida la primera gran industria de calzado de PVC en el país, con sus botas 7 VIDAS y su marca de calzado KIT [22].

Estos productos enfocados en la realidad contextual del ecuador de la época promulgaron el entendimiento de las necesidades de un pueblo mayoritariamente agrícola y obrero. Las botas "7 vidas" cuyo nombre nace de la analogía que hizo un cliente cuando se le solicitó prueba de producto antes de su lanzamiento, quien, en alusión a la creencia sobre la casi inmortalidad de los gatos, 
calificó así a la bota PICA y su marca de calzado KIT calzado escolar, deportivo y casual, que combina lona y suela de PVC, garantizando así una mayor durabilidad y resistencia a los usuarios, a la vez que permite el desarrollo de diseños variados y novedosos [23]. Luego en 1975, PICA apuesta por una nueva línea de negocio, dentro de la categoría de juguetes se fabrican los primeros Ciccio Bellos. En 1986 PICA se ratifica como líder en el mercado, esta vez con Bora Bora en la categoría sandalias, en donde su modelo insignia es hasta hoy el producto de mayor venta nacional "Beach Multi" [22]. Estos productos de dos campos distintos como la juguetería y el calzado calaron dentro de la percepción del consumidor ecuatoriano, creando un conocimiento intrínseco de la marca dentro del consumidor a partir de estos productos. Para 1999 con una trayectoria de varios años en Juguetes, PICA lanza hacia finales de la década una muñeca que ganó la preferencia del consumidor inmediatamente: Travelina, quien es hoy la muñeca con mayor venta histórica en él [22]. El desarrollo de esta muñeca, aporto al desarrollo como marca, siendo al uno de los referentes de una generación.

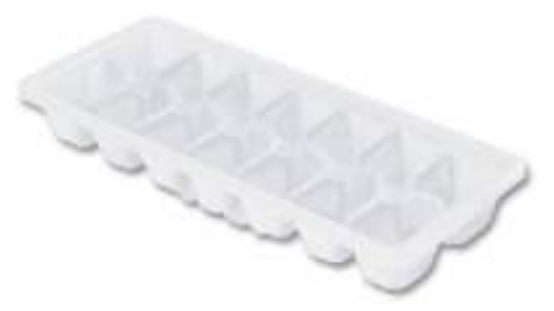

Figura 9. Cubeta de Hielos [22].

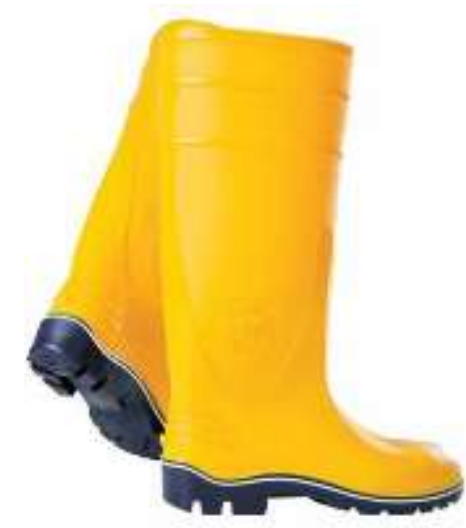

Figura 10. Botas PVC (7 vidas) [22].

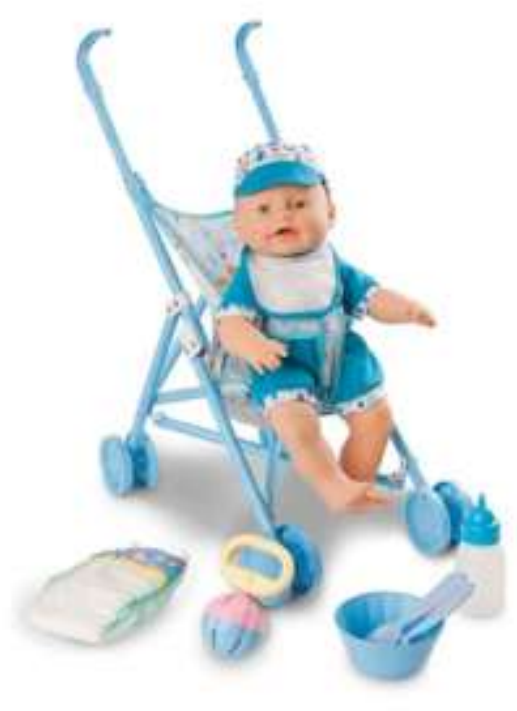

Figura 11. Coci Bello. [22].

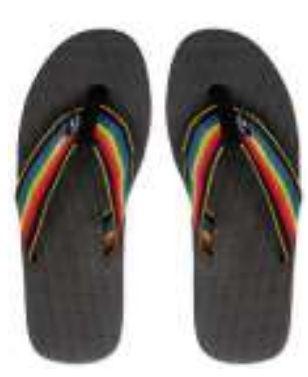

Figura 12. Zapatillas “Beach Multi” [22].

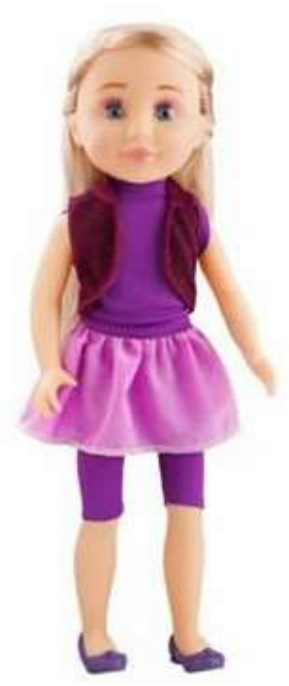

Figura 13. Muñeca travelina [22] 
La empresa Varma Carrocerías (1964) de acuerdo a su página oficial realizó el furgón de Molinos Poultier, como primer trabajo, dicha carrocería soportó carga por un espacio de tiempo de 30 años y desde enero de 1970 con una producción de hasta 30 carrocerías al mes [24]. El desarrollo de carrocería comenzó a fortalecer el desarrollo industrial dentro del Ecuador. Varma bajo el eslogan 'A la vanguardia de las carrocerías' la inversión, el diseño y la capacitación de la mano de obra son los sinónimos de calidad y los pilares de esta industria carrocera [25]. Aunque el desarrollo dentro del diseño de transportes y automóviles en Ecuador no presentan un factor de diferenciación adecuado. Varma ha logrado generar el involucramiento del diseño dentro del desarrollo de carrocerías. En la misma revista se da énfasis a el último de sus diseños el VM6. Denotando que el diseño aerodinámico y el confort permitieron competir con otras firmas carroceras en el mercado. En la actualidad es uno de diseños con más acogida por los transportistas de Loja, Guayaquil, Cuenca y otras ciudades [25].

En 1972 la época del "boom petrolero" y bajo el gobierno el Gral. Guillermo Rodríguez Lara, en Ecuador, comienza con la fabricación de esta camioneta llamada Aymesa Andino o como era popularmente conocido Andino [26] .

El Andino apareció como un proyectode Aymesa, bajo el diseño de Carlos Almeida, quien entonces trabajaba como asistente del departamento de ingeniería de dicha compañía. Se trató de una camioneta simple, con plataforma Bedford y motor Vauxhall de 1.4 litros[27].

El desarrollo de este producto no gozo de una aceptación adecuada dentro del mercado ecuatoriano sobre todo por la competencia generada por los automóviles extranjeros.

De acuerdo a los datos históricos presentados por Salazar, la empresa Aymesa presento dos diseños del auto andino: El primero era uno tipo jeep, con motor 1.2 litros y opciones de puertas de vinilo y puertas de metal con ventanas corredizas. Mientras que el segundo modelo era el conocido 1.4 litros con mejores acabados y opción pick up [27]. Este automóvil es el mayor intento del cambio de un Ecuador ensamblador a un país que involucra el diseño y la ingeniería para la creación de autos adaptados a las necesidades locales. En 2017, bajo el nombre de 'Andino Bacán'. Boris Mantilla, un diseñador industrial ecuatoriano especializado en Milán, propuso como tema de taller para Cromía un encuentro internacional de Diseño que se celebra en el Ecuador desde el año 2013 [28] el diseño del 'Nuevo Andino". Para el diario El telégrafo Mantilla manifestó que considera que si hay un sobreviviente del Andino es la tricimoto. "Es lo más parecido a un Andino. Es artesanal, no requiere de mucha tecnología, tiene elementos de fuerza, pero así mismo es de baja seguridad, muy peligroso, aunque los costos compensan esos defectos que lo trasladan solo a la periferia" [29]. A pesar de esta iniciativa en la actualidad, no se registran datos que puedan afirmar que el re diseño de este modelo este cerca de salir al mercado ecuatoriano.

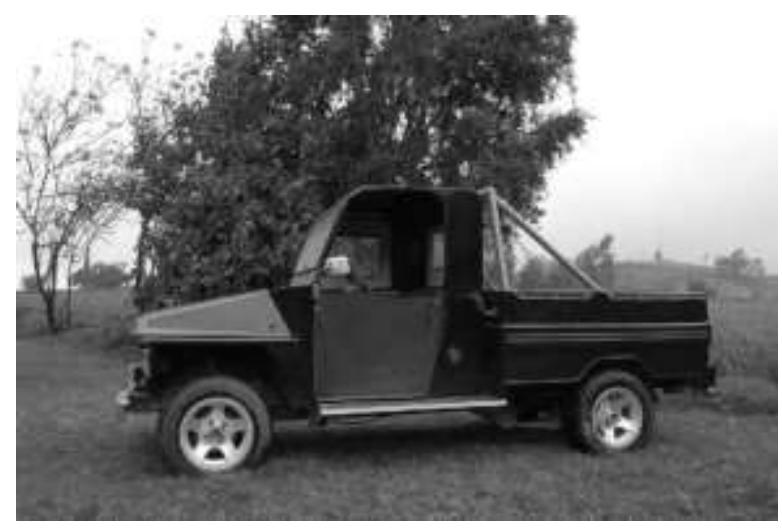

Figura 14. Auto Andino Modelo 1. [27].

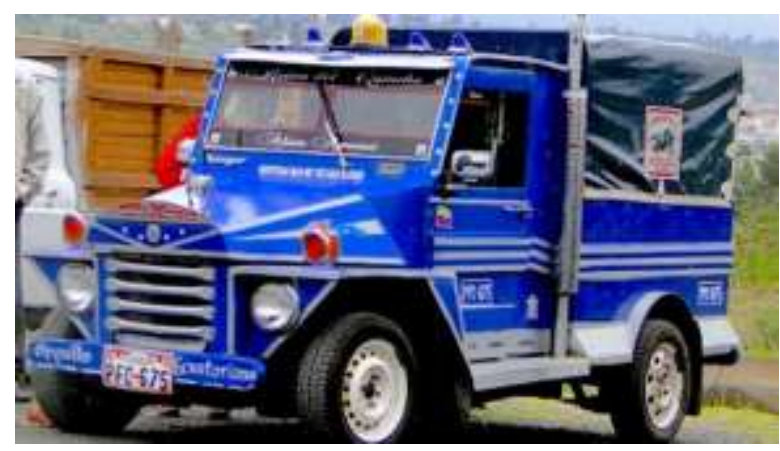

Figura 15 Auto andino modelo 2 [30].

Durante el mismo año de la creación del auto andino se funda Indurama en Cuenca (1972) comenzando con el ensamble de refrigeradores para luego dedicarse dedicándose a la fabricación de cocinetas de mesa, ollas enlozadas, calderos industriales y bicicletas. En 1982 Indurama inicia la 
producción en línea de cocinas y refrigeradores. Se establecen dos ejes para la fabricación de los productos: el diseño y la calidad. Entre 1997 a 2013 la empresa diseñó y produjo las líneas: Arian (1997), Viva (1998), Spazio (2000), Croma (2003), Avant (2006) y Quarzo (2010) [31].

Una de las empresas con un destacable empoderamiento de marca dentro de la industria mobiliaria es Colineal Corp, que comenzó como un pequeño taller en la década de los 40 [32]. Fue consolidada como pequeña empresa por Roberto Maldonado Álava en Cuenca en 1976 comenzó bajo el nombre de "Tienda de muebles", luego la misma necesidad hace que nazca Colineal, que es una fusión entre muebles coloniales y muebles lineales [33].

Desde sus inicios Colineal se destacó, entre otras cosas, por su atención al detalle, la calidad y el diseño [34]. Colineal aunque no presenta dentro de su creación involucración de profesionales del diseño representa la transición del artesano hacia una capacitación de diseño. Es sin duda, un generador de expansión de la industria de muebles. Colineal ha tomo influencias de ferias de diseño de mobiliario de Milán, Paris y Carolina del Norte [35]. Introduciendo conceptos del mercado extranjero a propuestas para una realidad nacional.

En el año 1994 Colineal se expande fuera del país y abre su primera tienda en Bogotá, en 2009 se abrió en la ciudad de Panamá, Panamá y desde 2010 está presente en Lima Perú con 3 tiendas [36].

\subsection{La formalización del diseño industrial en el Ecuador}

Para el desarrollo del siguiente apartado se analizará en orden cronológico la involucración de la académica en la formalización del diseño industrial como carrera dentro de las fibras tecnológicas y de educación superior ecuatorianas. Se tomarán las instituciones que han permitido el desarrollo de la disciplina y que han generado un desarrollo dentro de la institucionalización del diseño industrial.

De acuerdo a la información reposada en los archivos de las universidades ecuatorianas y a la recopilación de datos de SG Zeas Carrillo (2016), la Universidad del Azuay fue la primera que estimulo la enseñanza de las artes y oficios, en Cuenca en los años setenta ofertando las ramas de carpintería, cerámica, joyería y diseño textil como apoyo al trabajo artesanal. A partir de 1984, La Facultad de Diseño empezó a otorgar los primeros títulos profesionales.

El Diseño Industrial surge en Quito en 1985 con la creación del Instituto Metropolitano de Diseño "la Metro", esta institución comenzó con la formación de Diseñadores de productos desde 1981. A lo que se sumó en 1994 la formalización la Escuela de Diseño de la PUCE dicha universidad organizó la primera y segunda Bienal Universitaria del Diseño. Dentro del proceso ecuatoriano para la formalización del Diseño Industrial las carreras comenzaron con la influencia de escuelas latinoamericanas como la Universidad Nacional Autónoma de México (UNAM), quienes iniciaron en 1964 con la inserción del diseño industrial dentro de su plan curricular. Citando la información de Montaño los primeros profesores de las escuelas de diseño ecuatoriana fueron colombianos; de donde, surge la similitud curricular de ambos países.

La incorporación del diseño industrial a las redes de carreras ofertadas en el sistema de educación pública ecuatoriana se dio de la mano de la Universidad Central del Ecuador en el año 2005 de acuerdo a los datos reposados en la página web de la universidad. El enfoque de anexar la carrera de diseño industrial a una facultad de ingeniería es la de brindar un soporte técnico y de conocimiento de procesos industriales a los estudiantes.

En 2016 se realizó una reunión de universidades que ofertan diseño industrial "los directores de las carreras de las universidades Central del Ecuador, Azuay y Católica Ambato (PUCESA) decidieron reunirse con el propósito de compartir experiencias académicas y visualizar acciones que permitan difundir a la población en general los aportes profesionales y productivos del diseño industrial" [37].

En 2017 La Escuela Politécnica del Litoral en Guayaquil hizo el lanzamiento durante el primer periodo académico de dicho año de 5 carreras, dentro de las cuales se encontró la licenciatura en diseño de productos [38]. Siendo la última universidad del sistema público ecuatoriano que anexo una carrera de con directa relación al diseño industrial y siendo la primera del régimen costa.

En 2015, se crea la Cámara de Diseño del Ecuador como sociedad civil recibiendo su personería jurídica por parte del Ministerio de Cultura y Patrimonio (CADE, 2017). Esta sociedad representa Diseño 
Gráfico, Diseño de Interiores, Diseño de Vestuario y Moda y Diseño Industrial o deProductos.

En el mismo documento la Cámara establece que como representante de los profesionales del sector, ha apoyado al Gobierno en el proceso de Cambio de Matriz Productiva; al Ministerio de Cultura y Patrimonio en el Encuentro de Diseño para la edición de "Cromía", como parte del Consejo Consultivo en el 2014 y 2015, así como ha aportado y apoyado a leyes como la Ley Orgánica de Cultura, gestionado por el Ministerio al que representa o el Código INGENIOS gestionado desde el IEPI, tanto en la Asamblea Nacional como co-participantes en el foro de Diseño para la Emergencia: Código Abierto para el Pro-Común.

\section{Legislación y Leyes para el diseño industrial}

Dentro de la Legislación Ecuatoriana no existen al momento políticas públicas que respalden la actividad proyectual del diseño, o el diseño industrial en específico.

El Ecuador ha presentado mediante la Cámara de Diseño en colaboración con el Ministerio de Cultura y Patrimonio una agenda de desarrollo del diseño que culminara en 2020 donde se plantea "Formular políticas públicas encaminadas a reconocer, insertar y promocionar al diseño como herramienta para incrementar el desarrollo industrial, económico, regional y social, garantizando la participación del Estado, el sector empresarial, la defensoría del consumidor, la academia y los diseñadores".

La propuesta incluso teniendo el respaldo de un organismo central administrativo no logra generar una vía sólida para la realización de la propuesta.

Al no tener legislación que respalde los diseños industriales, la única manera de protegerlos en un marco jurídico es a través de La Organización Mundial de la Propiedad Intelectual (WIPO, por sus siglas en ingles) y debido a que Ecuador es contratante del Convenio de París se puede generar una protección internacional por concepto de dibujo y modelos industriales.

Esta organización define en su guía Looking Good desde una perspectiva legal a un modelo o diseño industrial como "An industrial design refers to the ornamental or aesthetic aspects of a producto" [39]. Lo que referencia que el diseño solo será protegido en cuanto a su ornamentación y aspecto estético.

El Programa Iberoamericano de Propiedad Intelectual y el Instituto Ecuatoriano de Propiedad Intelectual establecen que en Ecuador la única condición para que un diseño industrial sea protegido es la novedad, es decir, que este se diferencie claramente de un producto de su misma clase o similares [40].

\subsection{Diseñadores Industriales Ecuatorianos}

\subsubsection{Rodney Verdezoto.}

Dentro de los diseñadores Industriales con mayor trayectoria e impacto del Ecuador se encuentra Rodney Verdezoto. En una entrevista para Diseño en Ecuador se lo destaca como uno de los diseñadores industriales con más éxito del país. Dentro de lo cual se mencionan diseños como la silla Miró estuvo en la Feria Internacional del Mueble de Milán, diseñó el pabellón del Ecuador en la Feria del Libro en Bogotá y cuenta con más de 1000 proyectos dentro y fuera del país. Ha sido también docente universitario en varias universidades de Quito. En el 2009 fue nombrado director en Ecuador de la Red Latinoamericana de Diseño, cargo en el que se mantuvo hasta el 2013. En el 2012 Rodney fue invitado a participar en la Bienal Interamericana de Diseño [41].

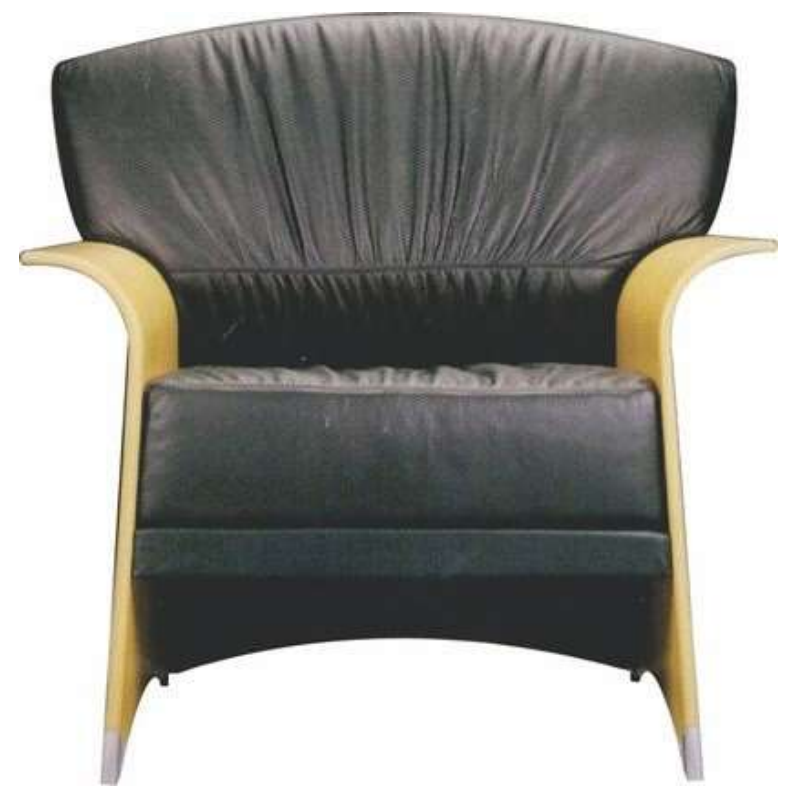

Figura 16. Sofá Excellence 1996 [41]. 


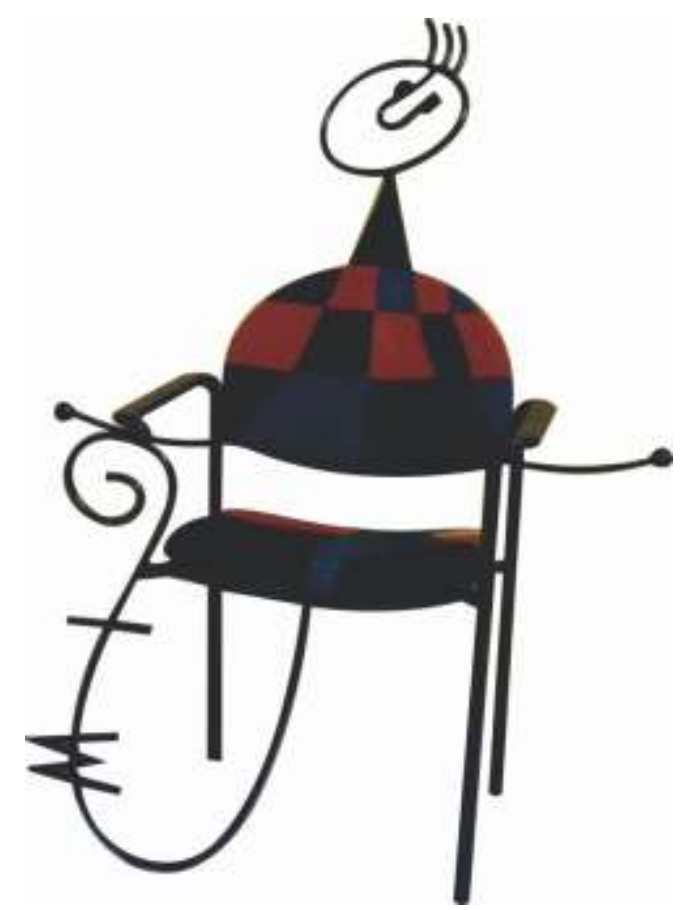

Figura 17. Silla Miró. 1998. Diseñada en ATU, fue expuesta en la Feria Internacional del Mueble de Milán [41].

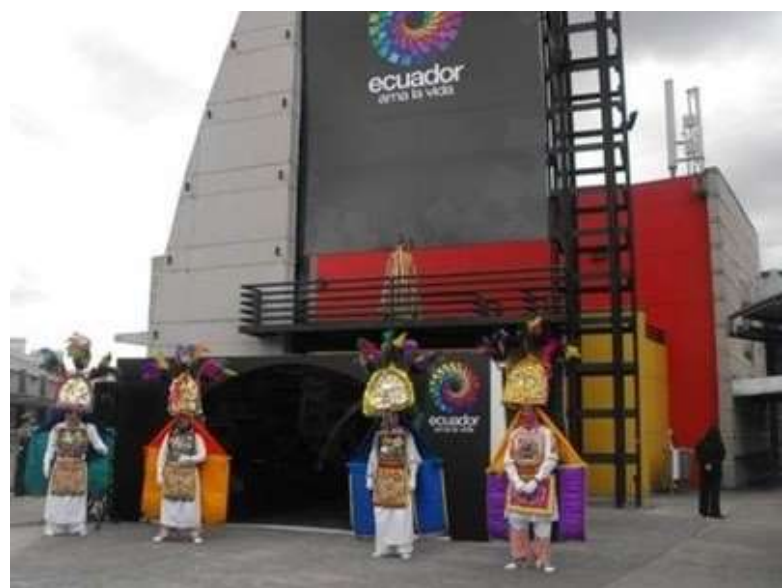

Figura 18 Pabellón Ecuatoriano para la Feria del Libro en Bogotá. 2011 [41].

\subsubsection{Raúl Guarderas}

Este diseñador industrial se definió como "el diseñador anónimo del Ecuador" mentando "Mucha gente usa productos que salieron de mi mente o fueron concebidos a través de mi lápiz. He diseñado, sillas, sillones, mobiliario y complementos de amueblamiento producidos por varias empresas de diversos sectores industriales y artesanales locales. He colaborado con empresas metalmecá- nicas pesadas, del sector cerámico, industria del sector plástico y pymes, con las que he lanzado al mercado productos fuera de lo convencional. He recibido premios en concursos y publicaciones de mi trabajo en revistas especializadas" [42].

Tal como menta Guarderas para el espacio web, es de los diseñadores industriales con mayor trayectoria y reconocimiento dentro del espacio territorial ecuatoriano.

Sus diseños abarcaron el mercado dentro de la reconocida marca de mobiliario ATU. A su vez, la línea de grifería diseñada para la empresa Edesa se produce hasta la actualidad con grandes réditos para dicha empresa.

Con su propia firma de diseño "MORF" realizó una gran cantidad de proyectos de interiorismo, montajes temporales, diseño de espacios retail y diseño industrial de varios productos, muchos de ellos aún en el mercado [42].

Uno de los campos mayormente explorados dentro del diseño industrial es el interiorismo y el diseño de mobiliario en lo cual Raúl Guarderas ha podido definir una línea adecuada de diseño.

Fue Jefe de Museografía del Museo Interactivo de la Ciencia siendo diseñador además de las exhibiciones permanentes y temporales hasta el año 2011. Desde entonces es consultor independiente y tiene su propio Hotel de Campo en Tambillo llamado "Sierra Alisos" [42].

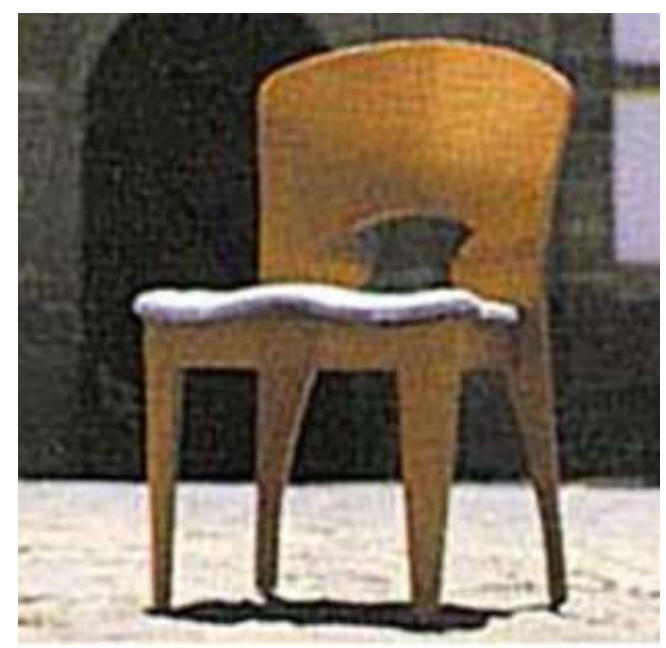

Figura 19. Silla Dashoa [42]. 


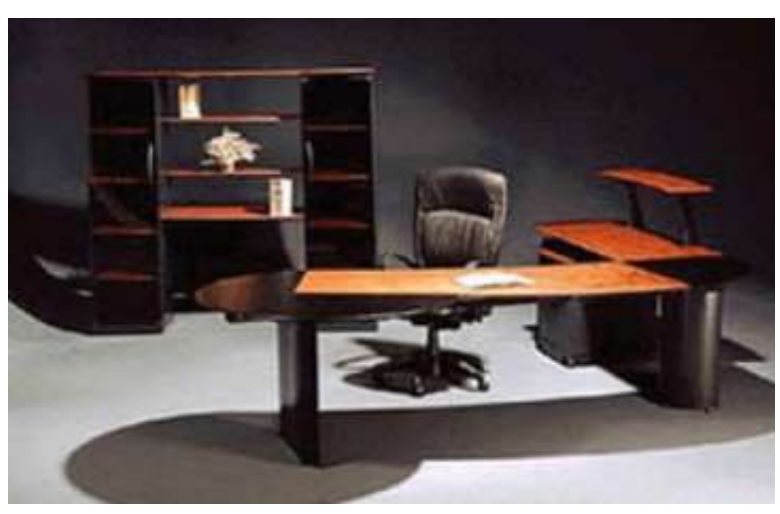

Figura 20. Sistema Adagio [42].

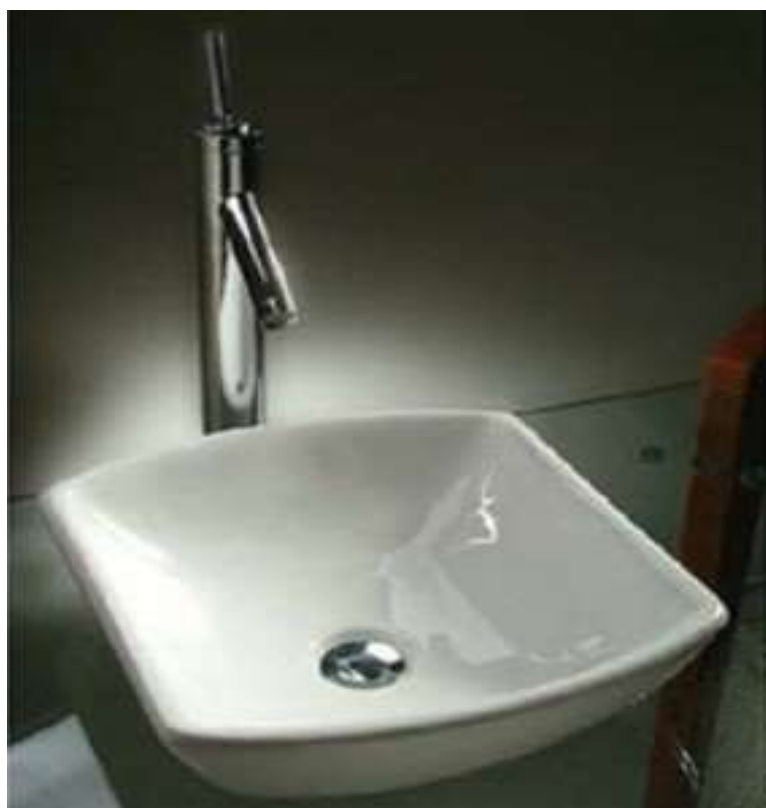

Figura 21. Vanitorio minimax [42].

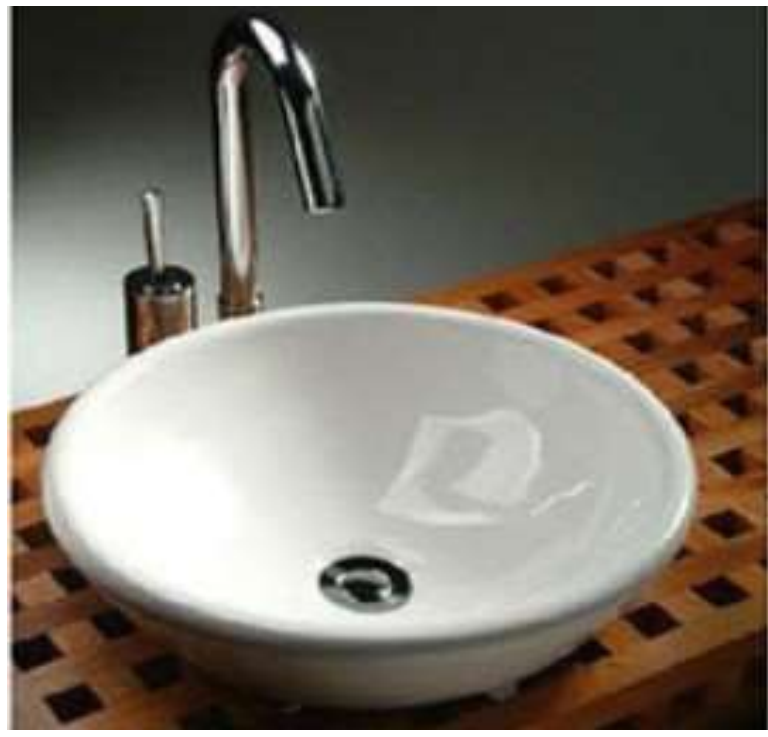

Figura 22. Vanitorio Tango [42].

\subsubsection{Arsenio García}

Nacido en Portoviejo, Ecuador en 1971. Arsenio García Monsalve comienza su vida artística de la mano de su madre la cuencana Mariela. En la adolescencia estudia cerámica en Cuenca, Ecuador y a los 17 años parte a Australia donde completa su iniciación en las artes con dibujo, pintura, escultura. Los siguientes años de su vida transcurren España, en donde estudia diseño gráfico, fotografía y diseño industrial.

Su pasión por el diseño de productos lo llevó a vivir en Estados Unidos en donde a formado parte de prestigiosas firmas de diseño como Herman Miller, Itoki, Omron, Toshiba, Starbucks, OXO International, Coca-Cola, Pepsi, Home Depot, Mc Donald's, Playtex, Hewlett Packard y otras. Su trabajo ha sido mostrado en publicaciones como Vogue Italia, Graphis, Time Magazine, ID Magazine, Innovation, Popular Mechanics, Fast Company, Ottagono, Oprah Magazine, etc [43].

Paralelamente, su amor por el arte ha hecho que continúe produciendo y mostrando sus obras, las que han participado en eventos internacionales de pintura, como en 1994 en Madrid en donde represento a Ecuador o en la Bienal Internacional de Pintura de Cuenca en abril de este año (Imaginario Ecuador, 2007).

Su trabajo ha sido reconocido con honores en el MoMA Design Store Destination NYC 2013, IDSA Gold Award, The Chicago Athenaeum Good Design Award, ID Magazine, etc; y se vende en The MoMA Design Store y en Design Within Reach [43].
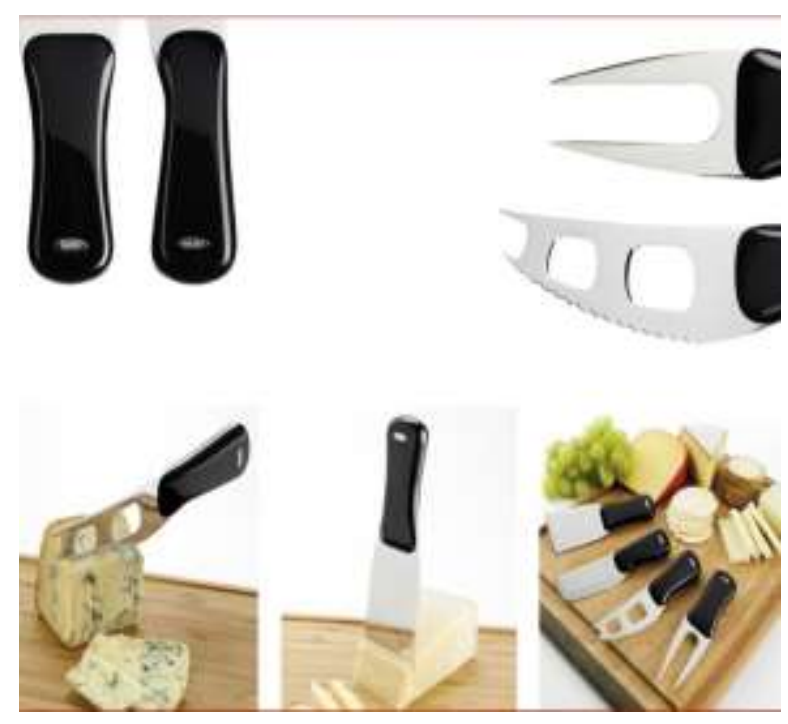

Figura 23. Set de Cuchillos para OXXO [43]. 


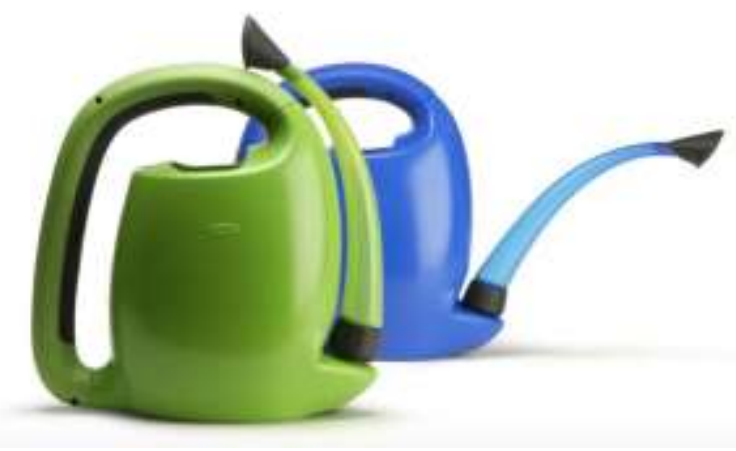

Figura 24. Regaderas para OXXO [43].

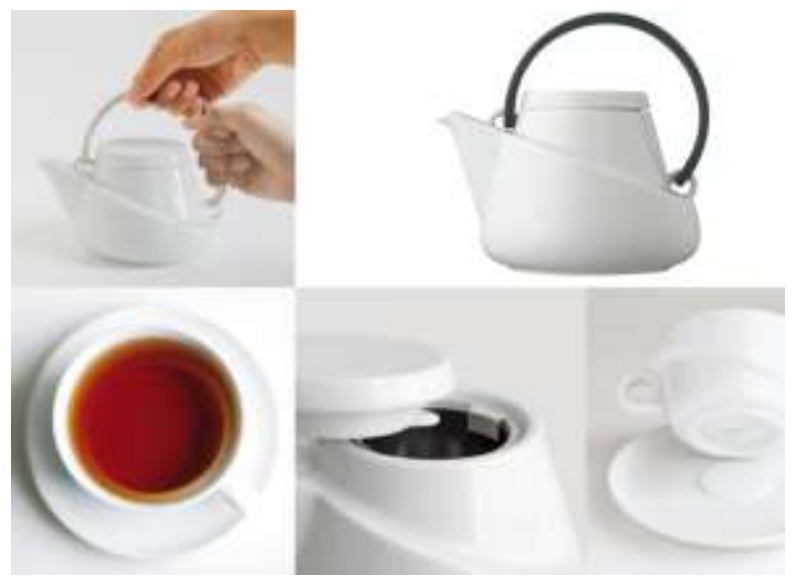

Figura 25. Tazas Ridge [43].

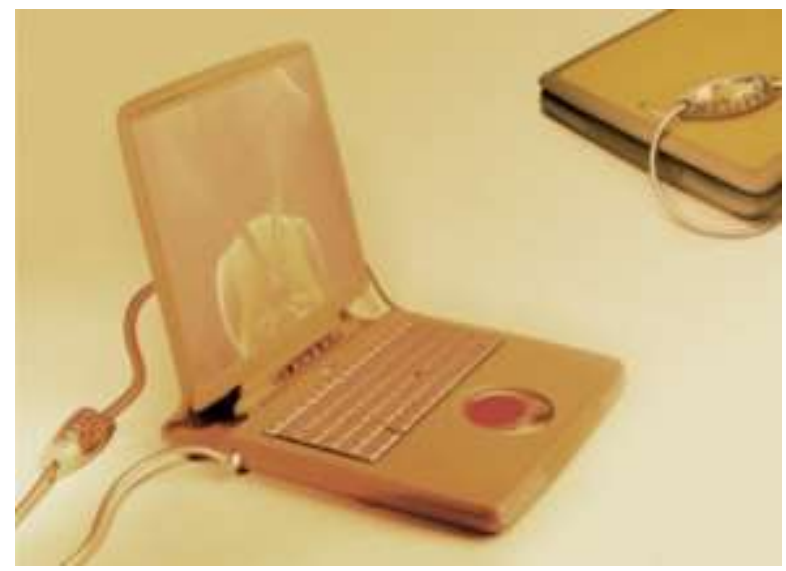

Figura 26. Concepto Laptop para Toshiba [44].

\subsubsection{Fernando Echeverría}

Fernando Echeverria Ruiz es un diseñador industrial quiteño, conocido por sus originales diseños en calzado y accesorios que ahora reside en Praga. Echeverria estudió Diseño de Productos en la Universidad Católica del Ecuador en Quito, posteriormente continuó con su Masterado en la Academia de Artes, Arquitectura y Diseño en Praga, con una especialidad en Footwear and Fusión Design, decidió quedarse en la República Checa en el 2010 y ahí creó su propia marca en el año 2014.

En Praga también se formó en el arte de la elaboración a mano de zapatos con maestros como Martín Lawart. Actualmente forma parte de la Bottega Smetana, un grupo de diseñadores locales con talleres en el centro de esa hermosa ciudad del Centro de Europa [45]. Este diseñador ecuatoriano presenta diseños de calzado y accesorios que han logrado abarcar el mercado global dentro de ámbitos de moda e indumentaria.

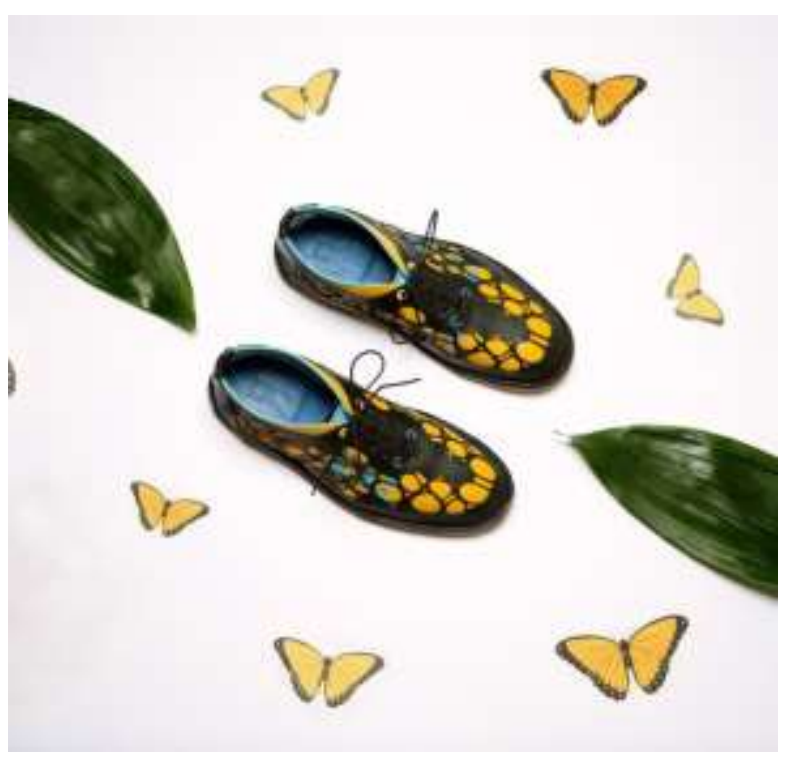

Figura 27. Zapatos Natura [46].

Este Diseñador Industrial establece que "Mi sello de identidad es ofrecer zapatos y accesorios que rescatan y usan técnicas tradicionales de la zapatería, pero que a la vez son diferentes y divertidos, buscando siempre la innovación estética y técnica pero no olvidando un principio: tener algo único que perdure. Por ejemplo, mis zapatos al ser de suela y al tener tacones de suela, después de un tiempo de uso es posible cambiarlos en cualquier zapatería del mundo, y volverán a estar como nue- 
vos, de igual manera la suela de mis zapatos es cosida a mano con el cuerpo del zapato lo que les da una vida larga" [47].

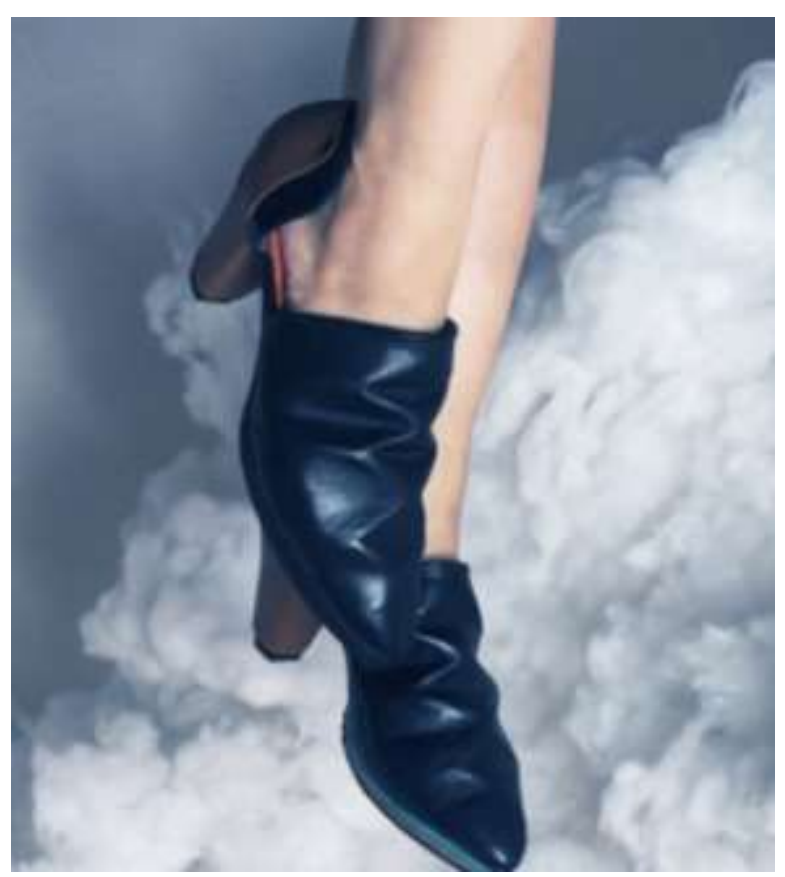

Figura 28. Zapatos Kubista [48].

La presentación de estos Diseñadores Industriales ecuatorianos tanto como sus proyectos desatacados y trayectoria establece el alcance del diseño industrial como disciplina y su amplio campo de acción.

\subsection{Oportunidades del diseño en el Ecuador.}

A pesar de los intentos gubernamentales por un cambio dentro de la matriz productiva ecuatoriana de migrar de un estado exportador de productos de consumo primario a productos con valor agregado. No se ha podido lograr un posicionamiento de los productos o servicios ecuatorianos en el mercado nacional e internacional.

"A través de diseño se logra concretar una forma de comunicación adecuada para comunicar el valor intrínseco del producto a los consumidores, el mismo que incide en la percepción de los consumidores. Se considera necesario enfatizar la falta de referencias al Diseño Industrial como un estimulante de la productividad para la industria ecuatoriana por parte de las políticas reguladoras de calidad, dejando así de lado uno de los prime- ros pasos para construir un producto de calidad, que no solo compita por el cumplimiento de especificaciones, sino también por imagen de marca, y conexión con el cliente" [49].

El anexo del diseño industrial en las entidades públicas y privadas es de vital importancia para un desarrollo económico y productivo adecuado. Pero dicho anexo debe estar regulado bajo regulaciones que permitan una correcta relación entre las partes.

El ocupar el diseño industrial como herramienta de desarrollo económico parece un poco osado, pero su relación está más cercana de lo que parece.

"El relacionar estos dos elementos es bastante simple, la economía y el diseño buscan solucionar problemas de espacio, tiempo, recursos, etc. Y todos relacionados y pensados para el ser humano en muchos casos. Se ayudan de otras ciencias y disciplinas para resolver problemas y no convertirse en problemas futuros, son cambiantes porque la sociedad es cambiante, buscan el bienestar de todos, estudian a sus públicos, infieren en el diario vivir [50].

Es así que dentro del desarrollo económico ecuatoriano el Diseño Industrial tiene una gran posibilidad de posicionamiento y desarrollo para un reconocimiento de productos ecuatorianos a nivel nacional e internacional.

Barbeito, Guillén y Martínez citan en su texto a Manuel Ibáñez Gimeno (2000) que plantea:

"Centrándonos en los factores internos, tenemos que uno de los factores genéricos es el diseño de los productos que tiene un impacto directo sobre la ventaja en diferenciación, aunque puede tenerlo también sobre los costes, ya que, el diseño del producto pensando en su fabricación, permite incrementar la productividad de la empresa al facilitar la fabricación del nuevo producto disminuyendo el número de piezas y el coste de materiales, la fabricación y el montaje, es decir, aumentado la productividad y reduciendo los costes de fabricación sin por ello disminuir los estándares de calidad ni olvidar la orientación al mercado del nuevo producto ni la aplicación de las nuevas técnicas de fabricación como son la ingeniería simultánea o el análisis de valor" [51]

Para contextualizar estas bases teóricas del aporte del diseño dentro de las fibras económicas de un 
estado. Se realiza la reseña de los resultados obtenidos por otros países que han involucrado el diseño dentro como factor económico. Uno de los cuales es el Design Council de Reino Unido que en su publicación del Design Economy Report (2016) y de acuerdo a una publicación de la Organización Diseño Publico se recoge como datos destacados del reporte lo siguiente:

- El diseño creo $£ 71.7$ billones en valor agregado bruto de UK (VAB, medición del valor económico generado por productos y servicios de un área específica). Equivalente al 7.2\% del total.

- Entre los años 2009-2013 el VAB de la economía del diseño creció a una taza mayor que el promedio de UK.

- En el 2013, las exportaciones que tuvieron un importante componente de diseño generaron $£ 34$ billones, constituyendo el $7.3 \%$ del total de las exportaciones de UK en dicho año. Esto ubica a UK quinto en el ranking del valor total de exportaciones generado por el diseño, detrás de Hong Kong, Suiza, Italia y Alemania.

- Personas que aplican conocimientos de diseño son $41 \%$ más productivos que el promedio.

- El diseño creó tres veces más trabajo que el promedio de las industrias, consolidando 1.6 millones de empleos.

- Los empleos creados se distribuyen con un tercio en empresas dedicadas al diseño, y el resto distribuido en distintos sectores [52].

A los que se le suman casos como Instituto Nacional de Tecnología Industrial de Argentina que reúne datos de un $71 \%$ de la base de firmas con actividades de diseño donde se presentan los siguientes datos:

\begin{tabular}{|c|c|c|c|}
\hline MPACTO & EIEvado: & $\begin{array}{l}\text { MEDio A } \\
\text { ALDUCioo }\end{array}$ & muto: \\
\hline Incremento de la facturación & $55 \%$ & $36 \%$ & $9 \%$ \\
\hline Aurnento de las exportaciones & $31 \%$ & $30 \%$ & $39 \%$ \\
\hline Apertura de nuevos mercados & $43 \%$ & $34 \%$ & $22 \%$ \\
\hline Rentabilidad & $31 \%$ & $43 \%$ & $26 \%$ \\
\hline Productividad & $32 \%$ & $33 \%$ & $35 \%$ \\
\hline Disminución de costos & $18 \%$ & $38 \%$ & $34 \%$ \\
\hline
\end{tabular}

Figura 29. Impacto económico de las actividades de diseño en Argentina [53].
Los datos recopilados en la Figura 29. Impacto económico de las actividades de diseño en Argentina evidencia el impacto del diseño en el incremento de la economía argentina, soportando así la importancia de la generación de los nexos del diseño y la industria.

Es así, que la inclusión del diseño industrial en mercado ecuatoriano de manera integrada tiene fuerte sustento para permitir el desarrollo económico a través de productos o servicios con alto valor agregado que aumentarían los réditos de las exportaciones y dinamizarían el mercado local.

\section{Conclusiones}

El diseño industrial representa la oportunidad del involucramiento de una gestión y un proceso adecuado para el lanzamiento de productos y/o servicios ecuatorianos exitosos en un mercado volátil.

El diseño industrial es una disciplina que, por las características de su naturaleza dentro de sus campos de acción, brinda respaldo dentro de la realización de objetivos importantes dentro de campos sensibles como la sostenibilidad. Siendo un ente que ofrece lineamientos claros y se relaciona con la solución de intereses sociales, culturales y políticos.

El diseño industrial en el Ecuador promete ser un cambio significativo dentro del desarrollo productivo del país, debido al enfoque de generación de ideas con alto valor agregado.

La existencia de referentes mundiales que al involucrar el diseño dentro del sistema productivo y empresarial han generado casos de éxitos con réditos económicos estimula la necesidad de mayor aporte en la definición de ejes y lineamientos claros de como el diseño con énfasis en el diseño industrial pueden penetrar las fibras económicas ecuatorianas.

\section{Referencias}

[1] J. V. d. Mercado, «El origen del diseño industrial,» 23 Enero 2013. [En línea]. Available: https://universidadanahuacsur.wordpress.com/2013/01/23/el-origen-del-diseno-industrial/. 
[2] Grupo Carman, «Diseño Insutrial: historia y evolución,»19 Marzo 2014. [En línea]. Available: https://grupocarman. com/blog/2014/03/19/diseno-industrial-historia-y-evolucion/.

[3] A. Gay y L. Samar, El diseño industrial en la historia, Córdoba: EDICIONES teC, 2007.

[4] A. Cárdenas, «Impecable,» 28 Diciembre 2007. [En línea]. Available: http:// impecable.blogspot.com/2007/12/historia-del-diseo-industrial-en.html.

[5] S. Fernandez y G. Bonsepie, Historia del diseño en América Latina y el Caribe, Sao Paulo: Blücher, 2008.

[6] L. Álvarez, S. Camacho, G. Maldonado, C. Trejo, A. Olguín y M. Pérez, «La investigación cualitativa,» Enero 2014. [En línea]. Available: https://www.uaeh.edu.mx/scige/boletin/tlahuelilpan/n3/e2.html.

[7] UNIVERSIDAD DE BOGOTA JORGE TADEO LOZANO, «¿QUÉ ES ELDISEÑO INDUSTRIAL? SEGÚN EL WDO (WORLD DESIGN ORGANIZATION),» UTADEO, 30 Octubre 2019. [En línea]. Available: https://www.utadeo.edu.co/es/ nuestra-produccion/observatorio-diseno-de-producto/219671/que-es-el-diseno-industrial-segun-el-wdo-world-design-organization.

[8] E. Vega, «Diseño para el consumo,» 2009. [En línea]. Available: http://paperback.infolio.es/articulos/vega/consumer.pdf.

[9] G. Rodriguez, «Manual de Diseño Industrial,» 25 Marzo 2016. [En línea]. Available: http://www.cua.uam.mx/pdfs/conoce/libroselec/16ManualDI.pdf.

[10] S. Llinguin, «La experiencia turístico-cultural de los visitantes en los museos del sombrero de paja toquilla de Cuenca-Ecuador, 2017-2018,» 26Junio 2019. [En línea]. Available: https://dspace.ucuenca.edu. ec/bitstream/123456789/32914/1/Trabajo\%20de\%20titulaci\%C3\%B3n.pdf\%20 TUR\%20275.pdf.
[11] E. Romero, «El verdadero origen de los tradicionales sombreros 'Panama Hat',» 9 Marzo 2018. [En línea]. Available: https://actualidad.rt.com/actualidad/265082-sombrero-panama-hecho-ecuador.

[12] Ministerio de Turismo, «Sombrero de paja toquilla es Patrimonio Cultural Inmaterial de la Humanidad,»04 Diciembre 2012. [En línea]. Available: https://www. turismo.gob.ec/sombrero-de-paja-toquilla-es-patrimonio-cultural-inmaterial-de-la-humanidad/.

[13] V. Arrocha, «Historia del sombrero Panamá que popularizo Theodoro Roosevelt,» El Mundo, 2015 Marzo 25. [En línea]. Available: https://www.elmundo.es/tendencias/2015/03/25/55116a13e2704ee917 8b456d.html.

[14] L. Fajardo, «Paja Toquilla,» La Piedra Chura, 2012 Marzo 25. [En línea]. Available: http://lapiedrachura11.blogspot. com/2010/03/paja-toquilla.html.

[15] Grupo Ekos, «Grandes Marcas Ecuador 2018,» 2018. [En línea]. Available: https://marcas.ekosnegocios.com/marcas/192-atu.

[16] Kapari Comunicación, «Huelga y toma de fábricas en ATU,» 7 Febrero 2019. [En línea]. Available: https://redkapari. org/2019/02/07/huelga-y-toma-de-fabricas-en-atu/.

[17] Grupo Ekos, «El colapso de ATU deja dudas,» 29 Abril 2019. [En línea]. Available: https://www.ekosnegocios.com/articulo/ el-colapso-de-atu-deja-dudas.

[18] Atu Artículos de Acero, S.A., «Escritorios Ejecutivos Chieti,» [En línea]. Available: https://1184-ec.all.biz/escritorios-ejecutivos-chieti-g1352.

[19] ATU, «Salas de Espera y Lounges Tandem,» ATU, Artículo de Acero, S.A, [En línea]. Available: https://www.vknow24. com/product_detail.php?c=sillas $\% 20$ tandem $\% 20$ y $\% 20$ para $\% 20$ salas $\% 20 \mathrm{de} \% 20$ espera\&p$=29$. 
[20] ATU, «Archivación Cabinet,» ATU Articulos de Acero, S.A, [En línea]. Available: https://1184-ec.all.biz/archivacin-cabinet-g1357.

[21] REVISTA CLAVE, «ATU DESIGN: MODERNIDAD Y ELEGANCIA,» REVISTA CLAVE, 06 Julio 2016. [En línea]. Available: https://www.clave.com. ec/2016/07/06/atu-design-modernidad-y-elegancia/.

[22] Plasticos Industriales C.A, «Historia,» 02 Julio 2019. [En línea]. Available: http:// www.pica.com.ec/nosotros.

[23] Superbrand, «Pica,» 16 Febrero 2019. [En línea]. Available: http://macrovisionmedia.com/superbrandsecuador/pdf_casos/ pica.pdf.

[24] Varma Carrocerías, «Historia,» 29 Julio 2019. [En línea]. Available: http://varma. com.ec/web/varma/historia/.

[25] Revista Lideres, «El diseño de buses, su valor extra,» 15 Enero 2018. [En línea]. Available: https://www.revistalideres.ec/ lideres/diseno-buses-extra-empresa-negocios.html.

[26] J. Casañas, «Los 3 carros orgullosamente ecuatorianos,» 13 Diciembre 2017. [En línea]. Available: https://somosciudad.byclaro.com.ec/los-3-carros-orgullosamente-ecuatorianos/.

[27] J. Salazar, «LA HISTORIA DEL AUTO HECHO EN ECUADOR,» 2016. [En línea]. Available: https://www.patiodeautos.com/general/la-historia-del-auto-hecho-en-ecuador/.

[28] CROMÍA, «Saludos y Bienvenidos a Cromía 2017,» CROMÍA, 2017. [En línea]. Available: http://cromiaecuador.com/.

[29] J. Zambrano, «Diseñadores piensan en un 'Andino Bacán',» 17 Diciembre 2017. [En línea]. Available: https://www.eltelegrafo. com.ec/noticias/cultura/10/disenadores-piensan-en-un-andino-bacan.

[30] M. Echeverria, «Andino «el carro divino»,» Motorbit, 2015 Noviembre 26. [En línea]. Available: https://info.motorbit. com/mx/andino-el-carro-divino/.
[31] Indurama, «47 años de experiencia,» 01 Agosto 2019. [En línea]. Available: https://www.indurama.com/es/content/ acerca-de-global.

[32] COLINEAL, «COLINEAL,» 15 Agosto 2019. [En línea]. Available: https://lanacion.com.ec/310769-2/.

[33] Marketing Activo, «Colineal : Colonial y Lineal,» 31 Julio 2012. [En línea]. Available: https://marketingactivo.com/colineal-colonial-y-lineal/2012/07/31/.

[34] GRUPO EKOS, «Grandes Marcas Ecuador 2018,» 2018. [En línea]. Available: https://marcas.ekosnegocios.com/marcas/205-colineal.

[35] F. Torres, «El mueble cuencano talla el desarrollo local,» 03 Noviembre 2011. [En línea]. Available: https://www.eltiempo. com.ec/noticias/economia/1/el-mueble-cuencano-talla-el-desarrollo-local.

[36] P. Roman, «Colineal,»13 Abril 2016. [En línea]. Available: https://prezi.com/0mmlr59ww6qy/colineal/.

[37] PUCESA, «I Reunión de Escuelas de Diseño Industrial del Ecuador,» 2016. [En línea]. Available: https://www.pucesa.edu. ec/i-reunion-diseno/.

[38] Diario El Universo, «6 carreras universitarias más en la Espol,» 15 Enero 2017. [En línea]. Available: https://www.eluniverso.com/noticias/2017/01/15/nota/5996977/6-carreras-mas-espol.

[39] World Intellectual Property Organization, «Looking Good,» 2019. [En línea]. Available: https://www.wipo.int/edocs/pubdocs/ en/wipo_pub_498_1.pdf.

[40] Plataforma Iberoamericana de Propiedad Intelectual dirigida a Empresas, «Diseños o Dibujos Industriales,» 2013. [En línea]. Available: http://www.cibepyme.com/minisites/ecuador/es/propiedad-intelectual/ propiedad-industrial/Disenos-Industriales/. 
[41] Haremos Historia, «RODNEY VERDEZOTO / DISEÑADOR INDUSTRIAL Y DE INTERIORES,» 8 Abril 2014. [En línea]. Available: https://www.haremoshistoria.net/invitados/rodney-verdezoto-diseador-industrial-y-de-interiores.

[42] Haremos Historia, «RAÚL GUARDERAS / DISEÑADOR INDUSTRIAL Y DE INTERIORISMO,» 14 Mayo 2014. [En línea]. Available: https://www.haremoshistoria.net/invitados/raul-guarderas-disenador-industrial-y-de-interiorismo.

[43] Haremos Historia, «DISEÑO INDUSTRIAL, PONER AL USUARIO PRIMERO / ARSENIO GARCÍA,» 17 Junio 2014. [En línea]. Available: https://www. haremoshistoria.net/noticias/diseno-industrial-poner-al-usuario-primero-arsenio-garcia.

[44] IMAGINARIO ECUADOR, «los objetos de arsenio,» IMAGINARIO ECUADOR, 4 Octubre 2007. [En línea]. Available: http://imaginarioecuador.blogspot. com/2007/10/los-objetos-de-arsenio.ht$\mathrm{ml}$ ?view=timeslide \& $\mathrm{m}=1$.

[45] Haremos Historia, «FERNANDO ECHEVERRIA / DISEÑO DE CALZADO Y ACCESORIOS DESDE PRAGA,» 7 Marzo 2018. [En línea]. Available: https://www. haremoshistoria.net/noticias/fernando-echeverria-diseno-de-calzado-y-accesorios-desde-praga.

[46] EL COMERCIO, «Un zapatero ecuatoriano conquista las vitrinas y pasarelas de $\mathrm{Eu}-$ ropa Central,» EL COMERCIO, 12 Abril 2017. [En línea]. Available: https://www. elcomercio.com/chic/zapatero-ecuatoriano-creativos-pasarelas-europa.html.

[47] A. Cuervas, «FERNANDO ECHEVERRÍA: TRADICIÓN A TODO COLOR,» 6 Abril 2016. [En línea]. Available: https:// socatchy.net/es/fernando-echeverria-tradicion-a-todo-color/.
[48] E. Fernando, «Kubista heel,» Fernando Echeverria, [En línea]. Available: http:// ferech.com/kubistaheel/. [Último acceso: 2019 Septimbre 03].

[49] F. Arroyo, D. Bravo, C. Buenaño y M. Rivera, «Importancia de la calidad para el desarrollo del diseño industrial en el Ecuador,» Julio 2018. [En línea]. Available: http://revistas.uide.edu.ec/index.php/ innova/article/view/565/1107.

[50] Universidad Autonoma Metropolitana , «EL DISEÑO INDUSTRIAL COMO ACTIVIDAD ECONÓMICA,» 21 Febrero 2017. [En línea]. Available: https://introduccionaldisenoindustrial.wordpress. com/2017/02/21/el-diseno-industrial-como-actividad-economica/.

[51] Diseño Público, «REPORTE MUESTRA QUE LA ECONOMÍA DEL DISEÑO APORTA£71.7 BILLONES A UK,» 2016. [En línea]. Available: http://disenopublico.org/reporte-economia-del-diseno-uk/.

[52] INTI, «Diseño en la Argentina: Estuio del Impacto Económico 2008,» Instituto Nacional de Tecnología Industrial, Buenos Aires, 2008.

[53] M. García, «Hecho en Ecuador: La historia de los autos ensamblados en el país,» Diario Expresso, 16 Noviembre2016.

[54] Diseño en Ecuador, «Haremos Historia,» 14 Mayo 2014. [En línea]. Available: https://www.haremoshistoria.net/ invitados/raul-guarderas-disenador-industrial-y-de-interiorismo. [Último acceso: 12 062019]. 